\title{
Research on wind turbine power performance based on the operation Data
}

\author{
Guanglei Li ${ }^{1 *}$, Dehua Wang ${ }^{2}$, Xiaoliang Liu ${ }^{3}$ and Peng Zhao ${ }^{1}$ \\ ${ }^{1}$ State Grid Shandong Electric Power Research Institute, Jinan,Shandong Province, 25002, China \\ ${ }^{2}$ Shandong Zhongshiyitong Group Co., Ltd., Jinan,Shandong Province, 25002, China \\ ${ }^{3}$ State Grid Weifang Power Supply Company, Weifang,Shandong Province, 261002, China
}

\begin{abstract}
The power characteristics are important for evaluating the operating state of the wind turbine. In order to accurately evaluate the performance of the actual 2.0MW wind turbine, this paper firstly collects the measured wind speed, power and other operational data reflecting the performance of the wind turbine, and analyzes the data according to the standard specification. On the basis of data analysis, this paper obtains the actual power curve of wind turbine, and then compares it with the theoretical power curve. Finally, this paper carries out comparative analysis and performance evaluation of wind turbine operation performance, and propose improvement measures on this basis.
\end{abstract}

\section{Introduction}

The generation capacity of a wind turbine depends on its power characteristics and wind energy utilization coefficient characteristics. Due to the big difference between the actual wind farm wind conditions and environmental conditions, there is a certain difference between the actual operation conditions and design conditions of wind turbines. In addition, there are other factors affecting the unit performance, such as the operation mode of the wind farm, equipment operation. Therefore, these factors will lead to the difference between the actual operation characteristics and the design of the wind turbine, which will affect the actual generating capacity of the wind turbine [1-3]. By measuring the actual operating parameters of the wind turbine, the characteristics of the wind turbine can be evaluated. This can not only verify the design performance of wind turbine units, but also judge the variation trend of unit performance in the long run.

\section{Project overview}

Wind turbine power characteristic test is mainly based on IEC61400-12-1. On this basis, the running state of the unit can be evaluated accurately. Based on these data, the annual generating capacity of wind turbines can be estimated, so as to analyze and explore potential faults of wind turbines. Therefore, it is very urgent for wind farm operators to test the power characteristics of wind turbines.

The power characteristics of wind turbines are mainly reflected in the following factors, such as power curve, annual generation capacity and power coefficient[4-5]. The external factors that affect the power characteristics of wind turbines are mainly composed of terrain, air density, atmospheric pressure and wind conditions [6-7]. Therefore, in order to accurately test the power characteristics, it is necessary to collect enough data covering a certain range of wind speed and atmospheric conditions. On the basis of these data, the power output characteristics of wind turbine are determined accurately through analysis and calculation. According to IEC61400-12-1 standard, this paper carried out the power characteristic test of wind turbine. The test flow is shown in Figure 1.

\footnotetext{
${ }^{*}$ Corresponding author's e-mail: lovexjtulgl@126.com
} 


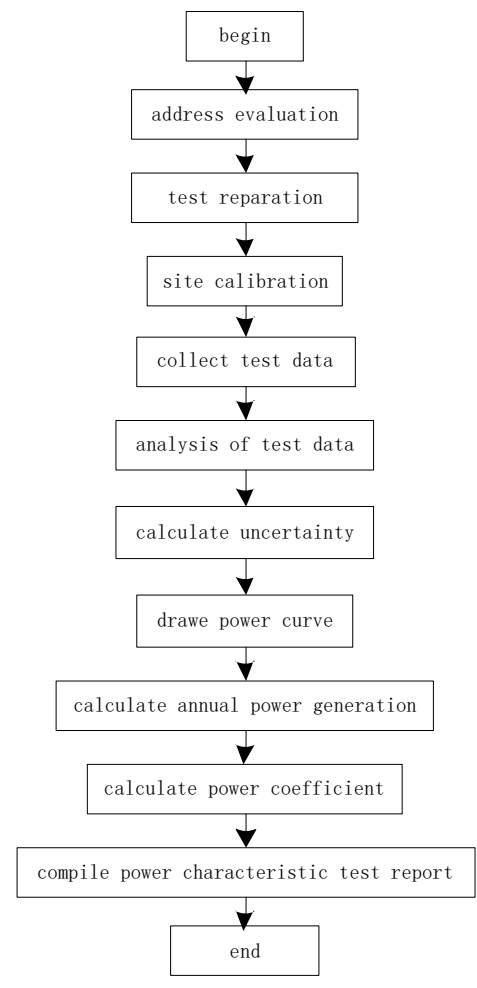

Figure 1. The process of wind turbine power characteristic testing

\section{Testing principle}

The wind turbine absorbs the wind energy through the wind turbine and converts it into the rotating mechanical energy of the wind turbine, which drives the generator to generate electricity and realize energy conversion [4-6]. When the wind velocity is $\mathrm{v}$, the wind energy acting on the impeller in unit time is calculated by the following formula.

$$
E=\frac{1}{2} \rho S v^{3}
$$

In this formula, $S$ is the swept area of the wind wheel; $\rho$ is the density of air.

Restricted by aerodynamic characteristics, wind turbines can only absorb part of the wind energy. According to baez theory, under ideal wind turbine conditions, the maximum power that a wind turbine can obtain from wind energy can be calculated by the following formula[6-9].

$$
P_{\max }=\frac{8}{27} \rho S v^{3}
$$

Thus, the theoretical maximum efficiency of the wind turbine is calculated as follows.

$$
C_{p}=\frac{P_{\max }}{E}=\frac{2 P_{\max }}{\rho S v^{3}}=\frac{16}{27} \approx 0.593
$$

In the above formula, it shows that the ideal wind wheel can only absorb a part of the energy from the natural wind, and other unabsorbed parts can be interpreted as the rotational kinetic energy left in the wake.
Because the wind turbine blade structure does not meet the ideal wind wheel conditions, and there are losses in the energy conversion links such as the transmission system and the generator. Therefore, for the actual wind turbine, the actual wind energy utilization factor is lower than the theoretical wind energy utilization coefficient. The useful power output actually obtained by a wind turbine can be expressed as follows.

$$
P=\frac{1}{2} \rho S v^{3} C_{p}
$$

Considering the limitation of generator capacity, the actual maximum output power of a wind turbine is called rated power. The relationship between the output power of the wind turbine and the wind speed is shown in the solid line in Figure 1. This relationship is called the power curve of the unit. This indicator is mainly used to reflect the performance of the wind turbine. As shown in Figure 1, the theoretical wind energy curve and the wind energy curve absorbed by the ideal wind wheel are given separately.

The power curve of a wind turbine can be divided into several wind speed segments. Meanwhile, the operation mode and characteristics of each wind speed segment are different. The main performance in the following aspects.

1) when the wind speed is lower than the incised wind speed, the wind power is too low to drive the wind turbine to rotate to generate electricity, and the wind turbine is in a static or idle state. In this case, the control system needs to monitor the wind speed. When the wind speed meets the condition of cut - in wind speed, the wind turbine starts to generate electricity.

2) when the wind speed is between the cut-in wind speed and the rated wind speed, the wind turbine can be 
integrated into the power grid. In this case, the wind power is lower than the rated power of the unit. In order to capture the maximum wind energy, the blade pitch Angle of the wind turbine remains unchanged at the maximum position. By controlling the speed of the impeller through the torque of the generator, the wind turbine can maintain the best tip speed ratio, which can ensure that the wind turbine can obtain the best wind energy utilization coefficient, and finally make the power curve as close as possible to the baez limit energy curve. Therefore, the performance of wind turbine mainly depends on the design and operation control effect of this wind speed section.

3) when the wind speed is between the rated wind speed and the cut-out wind speed, due to the limitation of the rated power of the generator, the output power of the wind generator set no longer increases with the increase of the wind speed, but keeps the output power constant through the control of the pitch Angle of the variable pitch.

4) when the wind speed is higher than the cutting speed, in order to avoid the damage of mechanical parts, the wind turbine is cut off and stopped, and the blade is adjusted to the position in the direction of the blade.

\section{Field test}

\subsection{Power characteristic Test of Wind Turbine}

A wind farm in Jiangsu province, is located in a coastal area rich in wind energy resources. The total installed capacity of the wind farm is 99MW. The units are all of a certain type of permanent magnet direct drive variable pitch 2.0MW. The diameter of impeller is $82 \mathrm{~m}$. According to wind data from the wind farm, the air density in this area is $1.228 \mathrm{~kg} / \mathrm{m} 3$, and the average annual wind speed at the height of $70 \mathrm{~m}$ is $7.4 \mathrm{~m} / \mathrm{s}$.

The wind tower is installed at a distance of $2.5 \mathrm{~d}$ from 159.35 degrees (due north is 0 degrees) of the unit under test. The air flow at the distance wind tower is less affected by the impeller disturbance of the unit and has a good correlation with the output power. The measuring tower is installed in strict accordance with the IEC standard to ensure the accuracy of measurement data. The power transmitter used to measure the power is installed at the wind turbine outlet.

Table 1. Conditions of other wind turbines around the test unit

\begin{tabular}{cccc}
\hline $\begin{array}{c}\text { Number of wind } \\
\text { turbine unit }\end{array}$ & $\begin{array}{c}\text { Distance from the unit } \\
\text { under test }\end{array}$ & $\begin{array}{c}\text { Relative bearing of the } \\
\text { unit under test }\end{array}$ & Rotor diameter \\
\hline FD05 & $723.39 \mathrm{~m}$ & 186.34 & $82 \mathrm{~m}$ \\
FD06 & $411.48 \mathrm{~m}$ & 238.89 & $82 \mathrm{~m}$ \\
FD08 & $617.79 \mathrm{~m}$ & 24.81 & $82 \mathrm{~m}$ \\
FD09 & $367.7 \mathrm{~m}$ & 333.15 & $82 \mathrm{~m}$ \\
FD10 & $664.44 \mathrm{~m}$ & 359.78 & $82 \mathrm{~m}$ \\
FD05 & $723.39 \mathrm{~m}$ & 186.34 & $82 \mathrm{~m}$ \\
\hline
\end{tabular}

\subsection{Data Processing}

Based on the collected data, the power characteristics are evaluated to accurately determine the power output characteristics of the wind turbine. These data should include parameters such as wind speed, wind direction, temperature, humidity and other external conditions. In addition, parameters for the operating state of the wind turbine such as the power output should be included. These data require that the hours of normal operation of the wind turbine need to be much longer than 180 hours.

The acquisition frequency is 10 minutes. The time interval is from October 9, 2017 to November 29, 2017, and the acquisition frequency is 10 minutes.
During the test cycle, the wind speed of the wind turbine appeared less frequently, so this test uses only one database for power characteristics testing.

\subsection{Test results}

The data sets selected from the test need to be converted back to the data at the two reference air densities [5]. One is the average value of the air density measured at the test site, the magnitude of the change is close to 0.05 $\mathrm{kg} / \mathrm{m} 3$, and the other is the air density value at sea level, refer to the ISO standard air density $(1.225 \mathrm{~kg} / \mathrm{m} 3)$. If the measured air density is in the range of $1.227 \mathrm{~kg} / \mathrm{m} 3$, there is no need to convert the air density. The power curve test results are shown in Table 2.

Table 2. Power curve data of wind turbine unit measured

\begin{tabular}{|c|c|c|c|c|c|c|c|c|c|c|}
\hline $\begin{array}{c}\text { Serial } \\
\text { number }\end{array}$ & $\operatorname{Bin}$ & $\mathrm{m} / \mathrm{s})$ & frequency & $\begin{array}{l}\text { active } \\
\text { power } \\
(\mathrm{kW})\end{array}$ & $\begin{array}{l}\text { wind speed } \\
(\mathrm{m} / \mathrm{s})\end{array}$ & $\begin{array}{c}\text { Power } \\
\text { variance }\end{array}$ & $\begin{array}{c}\text { power } \\
\text { coefficient }\end{array}$ & $\begin{array}{c}\text { Class A } \\
\text { Electrical } \\
\text { Power } \\
\text { Uncertainty }\end{array}$ & $\begin{array}{c}\text { Class B } \\
\text { Comprehen } \\
\text { sive } \\
\text { Uncertainty }\end{array}$ & $\begin{array}{l}\text { Comprehen } \\
\text { sive } \\
\text { Uncertainty }\end{array}$ \\
\hline 1 & 1 & 1.5 & 109 & 0 & 1.253 & 0.01 & 0 & 0.001 & 6.1 & 6.100 \\
\hline 2 & 1.5 & 2 & 169 & 0 & 1.75 & 0.01 & 0 & 0.001 & 6.2 & 6.200 \\
\hline 3 & 2 & 2.5 & 207 & 0.2 & 2.226 & 0.68 & 0.002 & 0.044 & 6.298 & 6.928 \\
\hline
\end{tabular}




\begin{tabular}{|c|c|c|c|c|c|c|c|c|c|c|}
\hline 4 & 2.5 & 3 & 231 & 1.6 & 2.728 & 2.81 & 0.031 & 0.181 & 6.308 & 6.939 \\
\hline 5 & 3 & 3.5 & 215 & 12.3 & 3.218 & 10.35 & 0.152 & 0.7 & 6.807 & 7.488 \\
\hline 6 & 3.5 & 4 & 242 & 35 & 3.738 & 15.01 & 0.27 & 0.958 & 8.059 & 8.865 \\
\hline 7 & 4 & 4.5 & 292 & 60 & 4.227 & 26.35 & 0.341 & 1.515 & 9.42 & 10.362 \\
\hline 8 & 4.5 & 5 & 367 & 96.2 & 4.757 & 38.97 & 0.376 & 2.009 & 10.417 & 11.459 \\
\hline 9 & 5 & 5.5 & 309 & 154.9 & 5.246 & 30 & 0.43 & 1.681 & 16.586 & 18.245 \\
\hline 10 & 5.5 & 6 & 362 & 209.6 & 5.742 & 38.53 & 0.445 & 2.008 & 15.668 & 17.235 \\
\hline 11 & 6 & 6.5 & 363 & 276.2 & 6.247 & 59 & 0.456 & 3.081 & 18.525 & 20.378 \\
\hline 12 & 6.5 & 7 & 329 & 353.4 & 6.736 & 70.56 & 0.466 & 3.876 & 22.53 & 24.783 \\
\hline 13 & 7 & 7.5 & 330 & 441 & 7.25 & 91.72 & 0.474 & 5.03 & 24.755 & 27.231 \\
\hline 14 & 7.5 & 8 & 346 & 546 & 7.746 & 98.85 & 0.482 & 5.295 & 31.231 & 34.354 \\
\hline 15 & 8 & 8.5 & 240 & 665.7 & 8.223 & 105.52 & 0.488 & 6.799 & 36.115 & 43.338 \\
\hline 16 & 8.5 & 9 & 271 & 779.8 & 8.72 & 148.16 & 0.48 & 8.924 & 35.288 & 42.346 \\
\hline 17 & 9 & 9.5 & 198 & 942.5 & 9.212 & 146.28 & 0.492 & 10.291 & 51.502 & 61.802 \\
\hline 18 & 9.5 & 10 & 161 & 1073.30 & 9.733 & 179.33 & 0.466 & 13.991 & 40.49 & 48.588 \\
\hline 19 & 10 & 10.5 & 149 & 1200.20 & 10.227 & 212.36 & 0.448 & 17.121 & 21.895 & 26.274 \\
\hline 20 & 10.5 & 11 & 138 & 1329.50 & 10.716 & 162.28 & 0.431 & 13.813 & 44.634 & 53.561 \\
\hline 21 & 11 & 11.5 & 129 & 1354.00 & 11.144 & 250.62 & 0.377 & 22.137 & 12.36 & 14.832 \\
\hline 22 & 11.5 & 12 & 115 & 1385.00 & 11.627 & 259.04 & 0.337 & 24.238 & 14.57 & 17.484 \\
\hline 23 & 12 & 12.5 & 78 & 1366.00 & 12.125 & 283.99 & 0.291 & 32.443 & 11.487 & 13.784 \\
\hline 24 & 12.5 & 13 & 65 & 1364.80 & 12.669 & 312.75 & 0.276 & 38.075 & 9.381 & 11.257 \\
\hline 25 & 13 & 13.5 & 30 & 1501.30 & 13.177 & 72.54 & 0.27 & 12.524 & 50.591 & 56.662 \\
\hline 26 & 13.5 & 14 & 23 & 1515.50 & 13.68 & 7.78 & 0.243 & 1.28 & 11.152 & 12.490 \\
\hline 27 & 14 & 14.5 & 26 & 1498.40 & 14.133 & 97.52 & 0.218 & 19.228 & 12.114 & 13.568 \\
\hline 28 & 14.5 & 15 & 16 & 1521.30 & 14.557 & 7.18 & 0.195 & 1.579 & 12.506 & 14.007 \\
\hline 29 & 15 & 15.5 & 16 & 1522.10 & 15.023 & 7.14 & 0.162 & 1.569 & 9.843 & 11.024 \\
\hline 30 & 15.5 & 16 & 8 & 1526.30 & 15.54 & 6.5 & 0.145 & 2.48 & 10.244 & 11.473 \\
\hline 31 & 16 & 16.5 & 10 & 1530.20 & 16.127 & 2.95 & 0.131 & 0.902 & 10.25 & 11.480 \\
\hline 32 & 16.5 & 17 & 2 & 1524.20 & 16.352 & 4.95 & 0.12 & 2.515 & 10.589 & 11.860 \\
\hline 33 & 17 & 17.5 & 3 & 1531.50 & 17.453 & 1.64 & 0.106 & 0.73 & 10.464 & 11.720 \\
\hline 34 & 17.5 & 18 & 7 & 1525.50 & 17.896 & 6.92 & 0.092 & 1.243 & 10.31 & 11.547 \\
\hline 35 & 18 & 18.5 & 2 & 1512.30 & 18.346 & 5.76 & 0.087 & 0.026 & 16.116 & 18.050 \\
\hline 36 & 18.5 & 19 & 4 & 1562.40 & 18.872 & 244.83 & 0.068 & 173.036 & 78.926 & 88.397 \\
\hline
\end{tabular}

The power coefficient of wind turbine reflects the ability of the unit to capture wind energy, and to a certain extent, which can reflect the operation state of the unit and even the design level of the machine. The power coefficient of the test unit is shown in Figure 2.

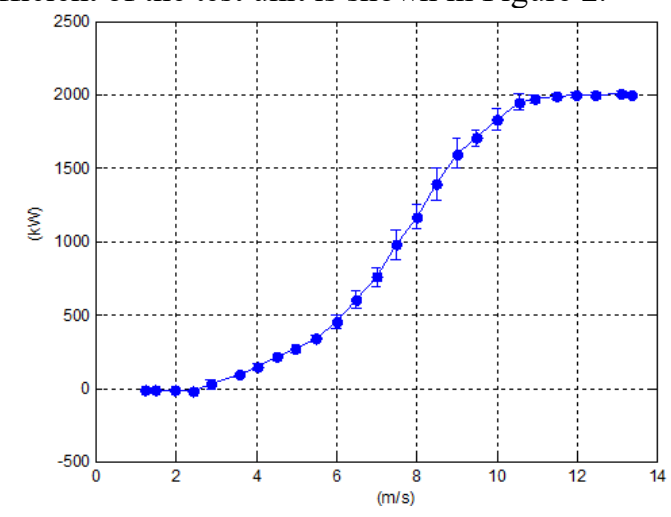

Figure 2. Calculation results of power curve interval

\section{Conclusion}

In view of the actual operation of $2.0 \mathrm{MW}$ wind turbines, this paper presents a performance evaluation method based on the measured data of wind turbines. After processing the data, the power curve of wind turbines is obtained, and the operation performance of the units is analyzed and judged.This paper provides an effective method for evaluating the performance of wind turbines and reliable data support for the evaluation of wind power generation.

\section{Acknowledgments}

This work was supported by Science and technology project of State Grid Corporation of China (Research and development of control and protection technology for 
flexible DC transmission of large-scale offshore wind power base)

\section{References}

1. Yang, Wenxian., Tavner, P J.., et al. (2014) Wind turbine condition monitoring : Technical and commercial challenges. Wind Energy, 17:673-693.

2. Li, Jian., Lei, Xiao., et al. (2014) Normal behavior models for the condition assessment of wind turbine generator systems. Electric Power Components and Systems, 42:1201-1212.

3. Yan, Yonglong., Li,Jian., et al. (2014) Condition parameter modeling for anomaly detection in wind turbines. Energies, 7:3104-3120.

4. Guo, Peng., Liu,Lin. (2018) Modeling and Monitoring of Multivariable Wind Turbine Power Curve. Power System Technology,42:3347-3354.

5. Zhang, Zijun., Kusiak, A.,et al. (2012) Monitoring wind turbine vibration based on SCADA data. ASME Journal of Solar Energy Engineering, 134:021004.

6. Dai,Juchuan., Liu, Deshun., et al. (2016)Research on power coefficient of wind turbines based on SCADA data. Renewable Energy, 86:206-215.

7. Zaher, A., Mcarthur, S., et al.(2009) Online wind turbine fault detection through automated scada data analysis. Wind Energy, 12: 574-593.

8. Kusiak, A., Li, Wenyan., et al. (2011) The prediction and diagnosis of wind turbine faults. Renewable Energy, 36: 16-23.

9. Kusiak, A., Verma, A., et al. (2013) Monitoring wind farms with performance curves. IEEE Transactions on Sustainable Energy, 4: 192-199. 